\title{
Editorial
}

\section{Free Open Access Science: A Challenging Future}

A colleague of mine, who works in salmon farming, frequently asks me for research papers in his field as he has no online subscriptions to access scientific articles. He has been asking why am I unable to access research that has been financed by the taxes I have paid? My friend is not the only person asking this question today.

As authors, we know that this situation arises all over the world and that it is due to our seeking out journals with high ISI impact, with the aim that our research work be published, yet without considering the visibility these publications may have in the areas where the studies were performed. Despite this, many researchers remain active, publishing work that can never be read by those who might be most interested, or by teaching staff at universities that have not subscribed to certain journals. This situation is repeated by researchers aiming to increase their chances of being granted funding for their projects, and then going on to repeat these practices.

Larger publishers offering journal subscriptions are now being threatened by the increase in free-access online journals. Free-access journals are passing on their editorial costs to the author, though free-access and high-impact journals charge elevated amounts for publication, which often give the author no credit in terms of financial compensation.

Meanwhile, journal editorial committees that maintain paid subscription models with payment are reducing the number of research articles in each published volume, with the aim of maintaining or increasing their impact factors, but they are inevitably confronted with the free-access model. Faced with this scenario, authors are caught between the dilemma of paying large amounts of money for publishing their research, or standing in line and being kept waiting.

For the European Community, from the year 2020 onwards, all research studies financed with public funding must be published in free-access journals. In the field of veterinary studies the situation remains largely unchanged and we, as authors, will probably not see ourselves in journals dedicated to very specific disciplines that have a small target audience.

In America there are still no clear policies about this, though what is known is that only a third of research publications go to open journals. A reversal of this situation could save the government millions of dollars per year in subscriptions to publishing companies, money that could instead be directed to increasing project financing. It may not even be unusual to see funding competitions to pay for publications.

Austral Journal of Veterinary Sciences Editorial Committee 